\title{
INTERACTIVE SIMULATIONS IN SUPPORT OF DECISION MAKING ON DEFENCE RESOURCE ALLOCATION
}

\author{
Todor TAGAREV, Gueorgui STANKOV, and Lozan BIZOV
}

\begin{abstract}
This article describes the approach and the experience of the Defence and Force Management Department at the "G.S. Rakovski" Defence and Staff College in conducting interactive simulations that support decision making on force structure, force development programs, and the respective allocation of resources. The primary purpose of the simulation is to educate students, mostly senior military and civilian MOD personnel, in the intricacies of defence planning in a changing environment, and to provide 'hands on' experience in defence programming and budgeting. In addition, it allows exploring the space of potential policy alternatives, force structuring and programming decisions, thus serving as a powerful decision support tool.
\end{abstract}

Keywords: Gaming, defence policy, long-term defence planning, defence capabilities, force structure, programming, budgeting, uncertainty, defence institution building.

In transparent defence management systems, the decisions on allocation of resources - personnel, weapon systems and equipment, infrastructure and money - are clearly related to policy objectives and priorities. However, the link between policy objectives and resource allocation is not straightforward. Intricate methods and models are used to define requirements, match a solution to a requirement, aggregate individual solutions, cost force structures, and manage the development of the armed forces.

But, as experienced defence policy makers and planers are aware, even in mature defence planning systems where the assumption is that rationality in decision making prevails, the provision of transparency is a daunting task. The armed forces are commonly expected to conduct diverse operations and perform variety of other tasks in conditions that often do not lend to advance specification. Perceptions and expectations of political leaders and societies change. Respectively, the amount of money 
they are willing to invest in defence is hard to predict, especially in mid- and longterm. People and organizations within the defence establishment aggressively compete for a share of the defence budget. And these are only a few among the factors that place force development and resource allocation decision making in a setting with inherent uncertainty. ${ }^{1}$

Yet, in a democracy, decision makers are accountable to the citizens for the way they use limited societal resources to raise and sustain armed forces. Therefore, a student of security and defence matters is expected to understand the principles of defence planning and resource allocation, including the principle of transparency, and to be aware of the need and the methods for preserving transparency under the impact of unforeseen events.

With this belief, in 2004 the leadership of the National Security and Defence faculty of the "G.S. Rakovski" Defence and Staff College in Sofia decided to include a game simulating defence planning and resource allocation decision making in the curricula of all of its master's programmes and a number of other courses. ${ }^{2}$ This paper presents the game and the supporting computer tool. Then it builds on the rich educational experience and provides ideas how such interactive simulation can be used as a decision support tool. The concluding part emphasises the usefulness of such decision-making simulations for the development of military and civilian expertise and the advancement of democratic civil-military relations.

\section{Goals and Objectives}

Primary goal of the simulation is to educate military and civilian students in the principles of defence planning and program-based defence resource management. It enhances the understanding of important linkages in defence policy making, force development and budget planning, provides first-hand experience in the process of linking security and defence policy objectives to program decisions to budget proposals, and allows the students to appreciate the role of key defence policy and planning documents. Further, the simulation increases the understanding of the ways uncertainty is accounted for and trains the students in the application of key mechanisms for incorporation of changes in the planning environment while preserving the integrity of a defence policy.

Second goal is role playing. As a result of the simulation, a participating student is expected to better understand the difference between expert and decision-making roles in designing defence policy and the particular interactions among variety of stakeholders - civilians and military, political leadership and experts, as well as among staff with various functional responsibilities. 
Third goal in the design of the simulation was to provide decision support to defence policy and resource allocation deliberations.

Fourth, and final goal, is relevant both to students and decision makers. Based on 'best practice' models, ${ }^{3}$ the simulation allows to compare existing and intended processes of defence resource decision making to the 'best practice' and to identify important process gaps. It is further useful in identifying data and information requirements, as well as necessary methodological, analytical and training support for efficient implementation of advanced defence planning and resource management.

This paper presents the way in which the Defence and Force Management Department at the "G.S. Rakovski" Defence and Staff College addressed these ambitious goals. ${ }^{4}$

\section{Approach}

To meet the stated goals and building on the IDA approach and tools, the team at the Defence and Force Management Department, led by Dr. Tagarev, designed an interactive simulation, or a game, under the title "Decision-making in managing force development." It is conducted with students in the master's programmes of the "National Security and Defence" faculty, as well as in a number of additional post-graduate courses.

The game usually runs for four days, with six hours in class each day. ${ }^{5}$ In addition, students are expected to work on game assignments in their time out of class.

\section{Structure}

The game is based on the security, economic and social environment and policies of a notional country, with a notional organization of decision making bodies and structure of the armed forces. It is organized in nine blocks: introductory block, seven interactive sessions, and a concluding block with discussion on practical challenges.

In the interactive sessions, in working groups of six to ten, game participants are tasked to:

1. Analyse the security and social environment and reach an agreement on defence policy objectives and priorities;

2. Analyse planning scenarios and derive capability requirements;

3. Agree on a draft defence programming guidance;

4. Design force development programmes;

5. Make programme decisions and propose a 'Program Decision Memorandum'; 


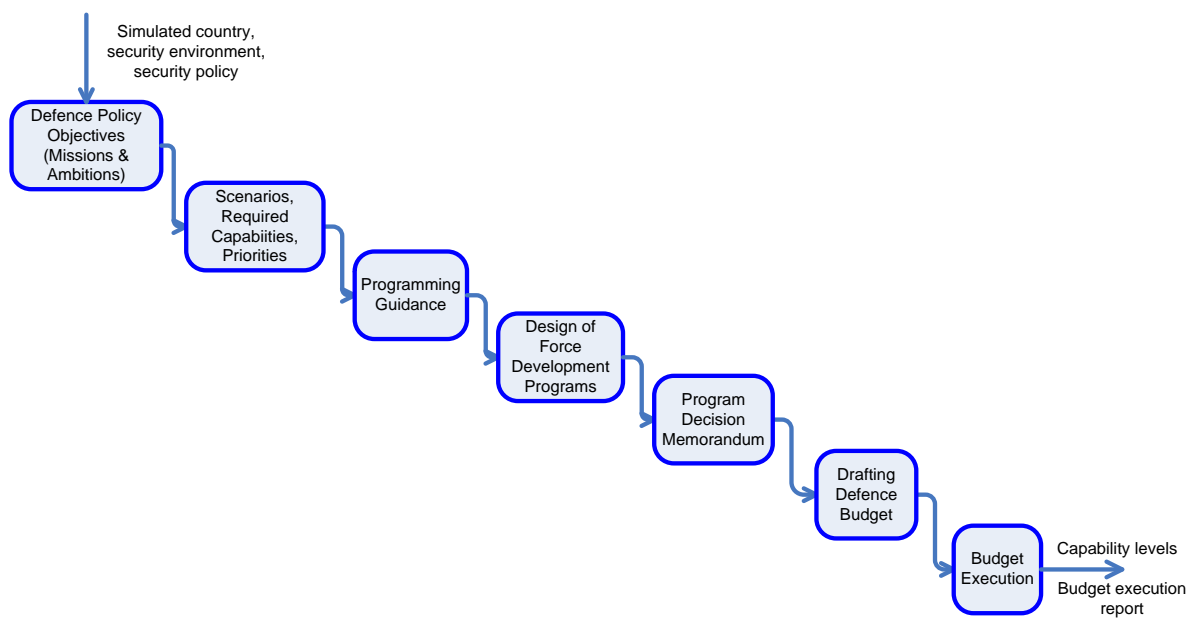

Figure 1: Process of Defence Resource Allocation, Used in the Simulation.

6. Discuss and propose a defence budget;

7. Propose changes in force development during budget execution and assess the impact on the level of defence capabilities.

This structuring of the game in sessions (or process phases, as presented in Figure 1) roughly emulates current best practice in defence policy making, programming and budgeting. ${ }^{6}$ One major difference is that the design of force development programs and the program decisions are included in the process of deciding on future force structure. One of the reasons - commonly acknowledged in the defence planning community - is that whether or not a future force structure is affordable and achievable depends to an extent on current situation (force size, operational engagements, legacy systems and their remaining life time). Another reason that is valid for Bulgaria and other countries with immature defence institutions, defence planning and financial management mechanisms, is that standing long-term defence plans, although sanctioned at the highest governmental level, ${ }^{7}$ are often unaffordable. What makes such cases even more complicated is that defence ministries sign procurement contracts not according to programmes, constrained by official budget forecasts, but as response to requirements in long-term plans, while additional procurement cases and other resource intensive proposals are pushed through the decision pipeline. And a third reason is practicality - such simplification allows shortening the duration of the game. Other simplifications are described in the next section of the paper. 
At the end of each session, the working groups report to a plenary. Thus, game participants are aware of and can compare alternative views. They are also tasked to identify advantages and disadvantages of selected alternatives.

\section{Roles}

During the interactive sessions game participants play roles. Depending on the session, each working group acts as:

- Defence Council in interactive session 1;

- Defence Requirements Council in interactive session 2;

- Programming Council in interactive sessions 3, 5,6 and 7; and

- Program Teams in interactive session 4.

Such advisory bodies and program teams really exist in the defence establishment of Bulgaria, what makes it easier for an experienced defence practitioner to associate himself or herself with the respective role, e.g. Deputy Minister of Defence on policy, on personnel, or on acquisition, Deputy Chief of the General Staff for Operations, Chief of Staff of the Land Forces, the Air Force, or the Navy, etc.

During the game each participant plays two types of roles - one that is close to his or her background, e.g. a military officer plays the role of a flag officer, and one that is atypical, e.g. an officer playing the role of a civilian deputy minister. This approach allows making the game rather realistic - approximately half the members of a simulated advisory body have relevant expertise and contribute to informed decision making, while often bringing in the views of and implicit loyalties to a particular defence organization. At the same time, each participant has the opportunity to get within the skin of "the other," to understand what drives them and better appreciate the respective rationale.

In the simulation, just like in real life, participants are tasked to act within a rational framework, but the decisions they make, collectively, reflect perceptions, individual experience and preferences, priorities, loyalties, etc. and, thus, are inherently subjective.

\section{Coping with Uncertainty}

During the game the participants, just like leaders of the defence establishment in real life, need to adapt previous decisions, plans and programmes to unforeseen events or other changes in the environment. In each realization of the simulation we prefer to use events that are clearly related to current burning issues. The following are among the events most often used in simulations: 
- The international community decides to intervene in a conflict region and the country decides to contribute, e.g. with a battalion-size unit, to allied force or a coalition. The approved defence budget does not foresee such contribution, while the decision of the Parliament to send troops abroad does not provide for additional financing. Therefore, the cost of the unforeseen participation has to be covered within the defence budget.

- A natural disaster occurs, e.g. floods, massive forest fires, etc. As a result, the government decides to finance certain activities in order to alleviate the negative consequences to the population. Part of that financing is from the previously forecasted or-depending on the game phase-approved defence budget.

- The Minister of Defence decides to make an expensive procurement, e.g. to buy a ship, within the budget planning phase or within budget execution, while such procurement is not included in the respective defence programme.

- An accident in a depot, storing surplus ammunition, leads to casualties among the civilian population and the government decides to speed up the process of utilization (without providing adding up to the defence budget).

- The economic and financial environment during implementation differs considerably from the one anticipated during planning and programming, for example:

- The real inflation is twice the forecasted one;

- The dollar value of the national currency increases (or drops) while payments on signed contracts are to be made in dollars;

- The price of fuel and, respectively, training cost increases dramatically;

- The labour market becomes more competitive and salaries need to be increased in order to make recruitment targets, etc.

Such events may be introduced in any of the interactive sessions and are always introduced in sessions six and seven.

Game participants are then tasked to find affordable solutions while still preserving the transparency of the linkages from security objectives to missions and defence ambitions to capability requirements and force structure to defence activities and capability levels.

In practice, the players are able to search only limited solution spaces through the feedback loops presented in Figure 2. 


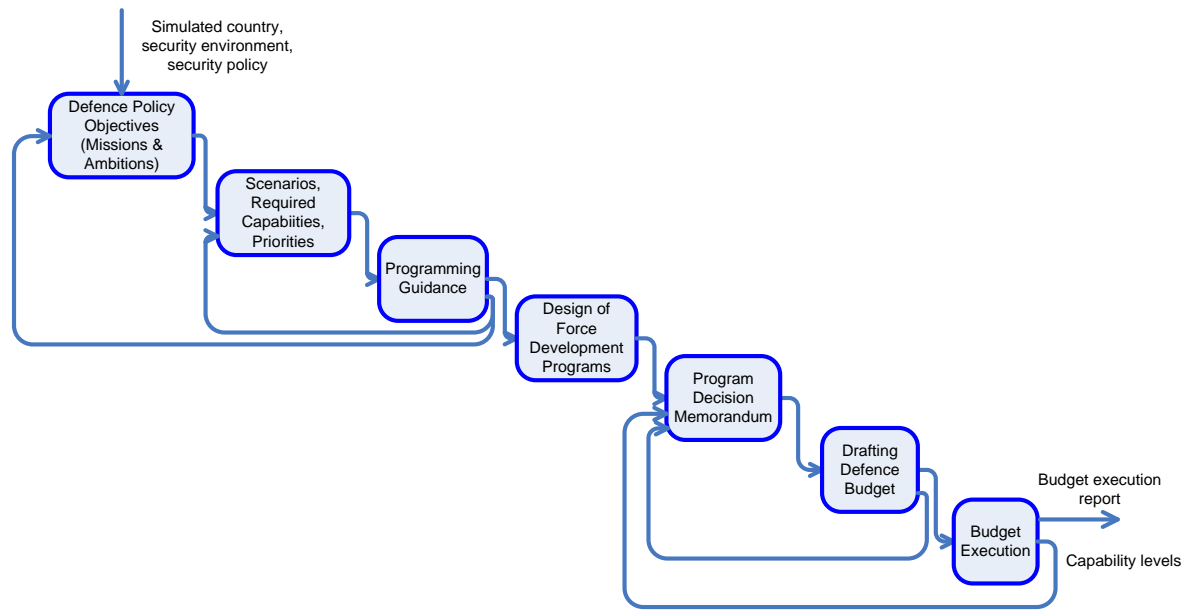

Figure 2: Relating Objectives, Force Structure, Programme and Budget Decisions in a Changing Force Development Environment.

\section{Supporting Computer Tool}

The conduct of the game is supported by a computer tool - a spreadsheet in Microsoft Excel. The tool automates all calculations, including costing, as well as the transition from programme costs to budget.

Relevant to the concept of the simulations, the tool is simple and realistic, allowing to keep focus on the main issues and leverages in force structuring and programming (see the middle column in Figure 3), namely:

- Manning levels;

- Percentage of conscripts among the enlisted personnel;

- Level of training;

- Major procurement projects;

- Disposal of excess equipment and infrastructure;

- Planned contribution to operations.

The tool automatically sums up data from all programmes, immediately visualizing main defence planning parameters. Figure 4, for example, provides a view on aggregated (potential) budget request highlighting the difference between the cost of all programmes and the fiscal guidance. In addition, the tool allows a straightforward merging from different sources, e.g. of programmes developed by two or more working groups. 


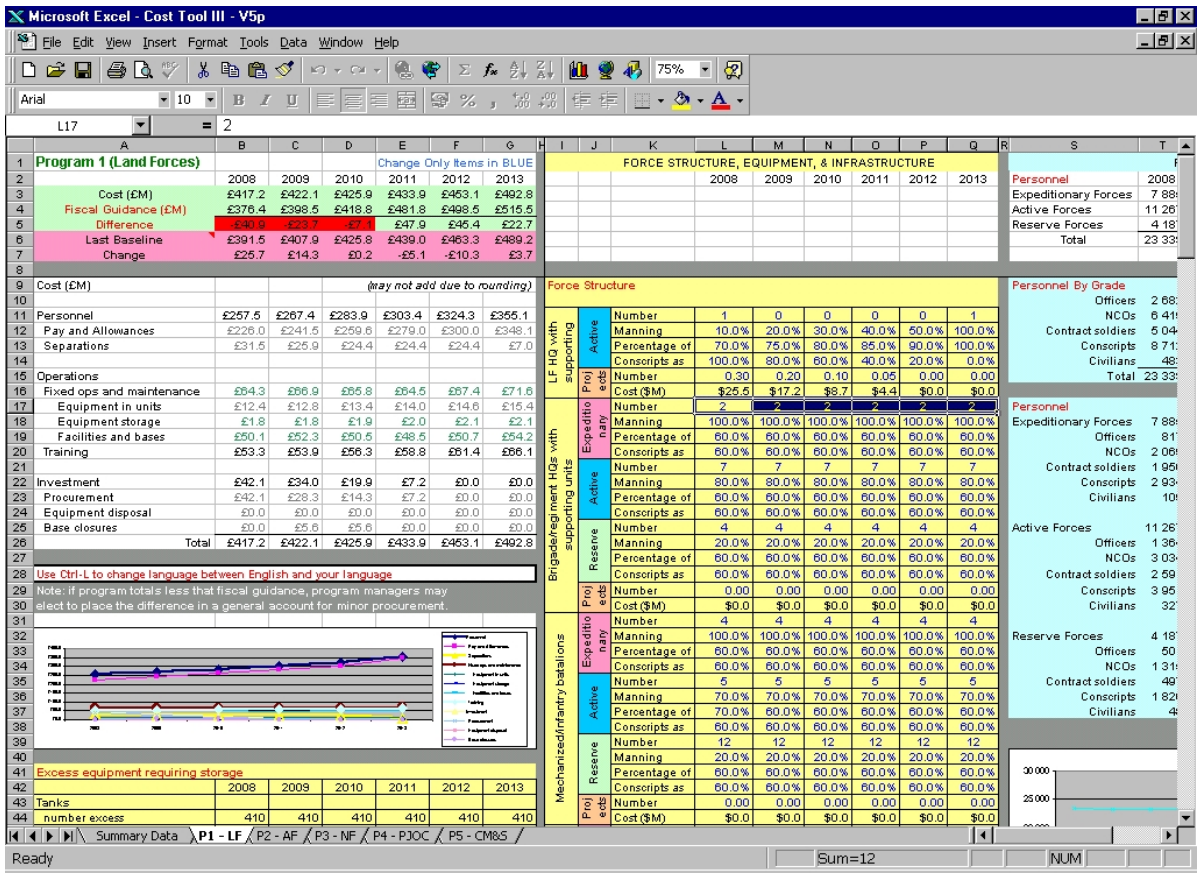

Figure 3: Designing Force Development Programmes - An Example.

The computer tool provides reasonable protection of the model structure and the inbuilt data from unauthorized interference by students. Thus, only instructors can make changes in the programme structure, costing factors, factors with impact on the fiscal guidance and other essential features.

Finally, the use of commercial-off-the-shelf software such as Excel spreadsheets is considered an efficient approach to the simulation - there are no special requirements for software licenses, installation and maintenance competencies, etc.

\section{Using the Simulation as a Decision Support Tool}

Over the last four years the simulation proved as one of the most effective ways for educating students in the complexities of defence policy making, planning, and resource management. For mid-career officers and civilians, as well as for new political appointees in the Ministry of Defence, it is particularly useful in revisiting major factors and clarifying relationships in setting defence policy and plans, translating policy objectives into budget decisions, and reiterating the need of a rational and transparent decision-making process. 


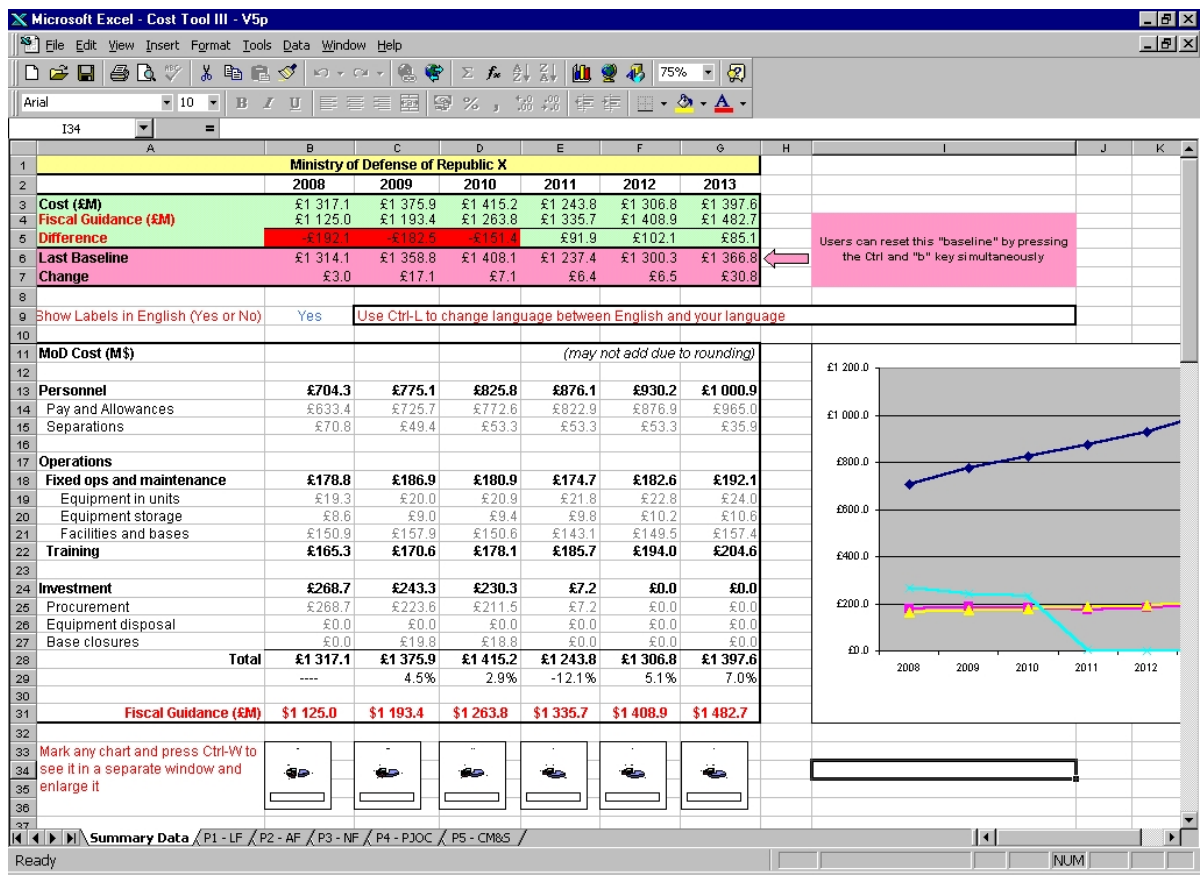

Figure 4: Summary Budget Data.

In addition, it is a promising tool to support the process of defence policy making and planning that was already used albeit with limited objectives.

First, such interactive simulation with decision makers, a role play or a mix of participants can be used to discuss and rationalise the major defence policy 'dimensions'-ambitions, operations, manpower policy, technological level and defence industrial ambitions, budget levels, etc. - and rationalize the process of prioritisation. It can be further used to generate rough approximations of qualitatively different force structure alternatives and thus quickly explore the space of viable force structures. With such alternatives in place, game participants may define and discuss pros and cons of force structures that are considered acceptable and can be sustained within anticipated defence budget levels. Given a change in the force development environment - the necessity to meet urgent and unforeseen requirements, macro-economic parameters that differ significantly from the ones used during programming and budget planning, etc. - the simulation can support the generation, analysis and selection of new programme alternatives with the consequent change of budget, readiness levels, procurement plans, etc. 
And a note of caution: It should not be expected out of such approach to get to detailed, meticulously costed force structure and programmes that could be turned directly into force development, budgeting or procurement decisions.

On two occasions in 2007, senior Bulgarian defence officials, including a deputy minister of defence, directors and department heads from the defence ministry participated in simulations conducted by the Defence and Force Management Department with mixed groups of senior officers and civilian students. Decision makers listened to and analysed working group reports during plenary sessions. The main interests in these cases were on (1) structuring and defining defence ambitions, (2) alternative approaches to partitioning defence capabilities, in particular the way in which alternative representation of capabilities are perceived, and (3) derivation of capability requirements from the analysis of planning scenarios. ${ }^{8}$

\section{Conclusion}

Interactive simulations as the one described in this paper make complex theories clearer and present students the chance to apply theoretical principles and approaches, develop critical thinking skills, and provide "a welcome relief from the everyday tasks of reading and preparing for classes." In fields with few absolutes like defence policy making, planning, and resource allocation, participants in a simulation can explore the main issues through experimentation, interacting with and learning from fellow students.

We found of particular value the creation of incentives through competition. ${ }^{10}$ Game participants are split in teams that are permanent throughout the game. All teams report on the same assignment at the end of each interactive session. And although faculty always claims that there is no school solution to the assignment, the motivation of students increases and teams almost without exception try to outperform the others. The additional benefit is the opportunity to check and compare the validity of the results against the solutions of other teams.

Finally, our experience confirms and reinforces the finding that human gaming is essential in exploratory analysis supporting defence planning amidst massive uncertainty. ${ }^{11}$ Hence, the interactive simulation holds the promise of a powerful tool in support of decision making on defence policy, planning and resource allocation.

\section{Acknowledgement}

This paper reflects research on project SfP 981149 "Operations Research Support to Force and Operations Planning in the New Security Environment," sponsored by NATO's Scientific Affairs Division in the framework of the Science for Peace Program. 


\section{Notes:}

1 Paul Davis calls this uncertainty 'massive' and 'ubiquitous.' For details refer to Paul K. Davis, "Lessons from Defense Planning and Analysis for Thinking about Systems of Systems," WR-459-OSD, Prepared for the Symposium on Complex System Engineering (Santa Monica, CA: RAND Corporation, January 2007); Paul K. Davis, "Strategic Planning Amidst Massive Uncertainty in Complex Adaptive Systems: the Case of Defense Planning," in Unifying Themes in Complex Systems, vol. IIIB: New Research, ed. Ali A. Minai and Yaneer Bar-Yam (Berlin: Springer, 2006), 201-214.

2 This decision was made under the impact of a very successful one-week game, conducted in the "G.S. Rakovski" Defence and Staff College at the end of 2003 by the U.S. Institute for Defense Analysis (IDA, <www.ida.org>). The authors gratefully acknowledge the impetus provided by IDA in 2003 and the permission to use the supporting tools. Since 2004, both the concept for the game and the supporting tools underwent considerable evolution, in which the authors played key roles. Therefore, the authors bear full responsibility for the text presented herein.

3 See Handbook on Long Term Defence Planning, RTO Technical Report 69 (Paris: NATO Research and Technology Organization, April 2003), <www.rta.nato.int/Pubs/RDP.asp? RDP=RTO-TR-069>; Guide to Capability-Based Planning, TR-JSA-TP3-2-2004 (TTTCP Joint Systems and Analysis Group, Technical Panel 3, MORS Workshop, October 2004), <www.mors.org/meetings/cbp/read/TP-3_CBP.pdf>; and Todor Tagarev, "Introduction to Program-based Defense Resource Management," Connections: The Quarterly Journal 5, no. 1 (Spring-Summer 2006): 55-69, <https://consortium.pims.org/introduction-toprogram-based-defense-resource-management-0>.

4 The first two of the goals are educational. The latter two were addressed within project SfP 981149 "Operations Research Support to Force and Operations Planning in the New Security Environment," financed partially by the NATO Science for Peace programme.

5 Alternatively, the game may be conducted in three days with eight hours in class per day. One class hour equals 45 minutes. Thus, the game includes eighteen astronomic hours in class.

6 For details the reader may refer to Todor Tagarev, "The Art of Shaping Defense Policy: Scope, Components, Relationships (but no Algorithms)," Connections: The Quarterly Journal 5, no. 1 (Spring-Summer 2006): 15-34, <https://consortium.pims.org/the-art-ofshaping-defense-policy-scope-components-relationships-but-no-algorithms>; and Todor Tagarev, "Introduction to Program-based Defense Resource Management."

7 For example Bulgaria's "Plan for Organizational Development and Modernization of the Armed Forces till 2015," approved by the Council of Ministers with Ordnance \# 301 of 2004, State Gazette 103 (November 2004).

8 At the time these were novel and methodologically challenging issues for policy makers and planers in the Ministry of Defence.

9 Michael D. Kanner, "War and Peace: Simulating Security Decision Making in the Classroom," PS: Political Science \& Politics 40, no. 4 (October 2007): 795-800.

${ }^{10}$ For this and other principles of using interactive simulations with senior defence personnel refer to Hari Bucur-Marcu and Cătălin-Marius Târnăcop, "Defense Institution Building: Training in Support of Defense Planning," Connections: The Quarterly Journal 5, no. 1 (Spring-Summer 2006): 103-115. 
${ }^{11}$ Davis, "Strategic Planning Amidst Massive Uncertainty in Complex Adaptive Systems: the Case of Defense Planning."

TODOR TAGAREV - Information about the author is available on page 114 of this volume.

LTC GUEORGUI STANKOV is a Chief assistant professor in Defense and Force Management, National Security and Defense Faculty, "G.S. Rakovski" Defense and Staff College. His work is focused on acquisition and project management. His previous assignments are in the J6 Bulgarian General Staff (2000-2004), Military Research Institute (1992-1999) and Operational Training Center (1989-1992). LTC Stankov has a master's degree in computer science from Higher Military Artillery School (1989). He is a graduate of Command and General Staff College at Ft. Leavenworth, Kansas, USA (2000). He has a master's degree in economics from Sofia University and Erasmus University, The Netherlands, 2004. E-mail: gstankov@abv.bg.

Major LOZAN BIZOV - Information about the author is available on page 78 of this volume. 